\title{
Comparasi Edge Detection Roberts dan Morfologi Pada Deteksi Plat Nomor Kendaraan Roda Dua
}

\author{
Dedy Abdullah ${ }^{1}$, Erwin Dwika Putra ${ }^{2}$ \\ ${ }^{1}$ Fakultas Teknik, Universitas Muhammadiyah Bengkulu \\ Jl. Bali, Bengkulu 38119 \\ Email : dedyabdullah@umb.ac.id \\ ${ }^{2}$ Fakultas Teknik, Universitas Muhammadiyah Bengkulu \\ Jl. Bali, Bengkulu 38119 \\ Email :erwindwikap@gmail.com
}

\begin{abstract}
-.
Refers to the difficulty factor on the detection plate on this research will focus on the detection of two-wheeled vehicle number plate, where the data will be taken from the farm garage. The resolution of this problem will be attempted using techniques of digital image processing method of detection of edge (edge detection) and morphology. Study on the evaluation and the research results will be calculated using the technique of confussion matrix, this technique will measure on the success rate of approach will be obtained from the proposed method. of the proposed method is sufficiently high, namely 53\% success rate, while the value of positive predictive value by which this value to know the success rate of the method to detect the entire image test is still extremely less just reached $40 \%$ success, while the value of negative value which is the value of preditive to know separation detection noise his success pretty well with a value of $56 \%$ success rate
\end{abstract}

Keyword: Edge Detection, Morfologi, Confusion Matrix

\begin{abstract}
Abstrak-.
Mengacu pada faktor kesulitan pada deteksi plat maka pada penelitian ini akan berfokus pada deteksi plat nomor kendaran roda dua, dimana data akan diambil dari lahan parkiran. Penyelesaian masalah ini akan dicoba menggunakan teknik pengolahan citra digital yaitu metode deteksi tepi (edge detection) dan morfologi. Pada penelitian ini evaluasi dan hasil penelitian akan dihitung menggunakan teknik confussion matrix, dimana pada teknik ini akan mengukur pada pendekatan tingkat keberhasilan yang akan didapat dari metode yang diusulkan. dari metode yang diusulkan cukup tinggi yaitu 53\% tingkat keberhasilan, sedangkan nilai positive predictive value dimana nilai ini untuk mengetahui tingkat keberhasilan metode untuk mendeteksi seluruh image uji masih sangatlah kurang hanya mencapai $40 \%$ keberhasilan, sedangkan nilai negative preditive value yang merupakan nilai untuk mengetahui pemisahan deteksi noise keberhasilannya cukup baik dengan nilai 56\% tingkat keberhasilan
\end{abstract}

Kata Kunci: Edge Detection, Morfologi, Confusion Matrix

\section{Pendahuluan}

Identifikasi plat nomor kendaraan pada perkembangan penelitian saat ini lebih banyak menggunakan objek kendaraan roda empat, seperti yang dilakukan putra dkk yaitu meneliti perbandingan metode pengolahan citra digital Fuzzy C-means dan Otsu untuk segmentasi plat nomor kendaraan. Objek yang digunakan pada penelitian ini menggunakan plat nomor kendaraan beroda empat [1].

Mengacu pada faktor kesulitan pada deteksi plat maka pada penelitian ini akan berfokus pada deteksi plat nomor kendaran roda dua, dimana data akan diambil dari lahan parkiran. Penyelesaian masalah ini akan dicoba menggunakan teknik pengolahan citra digital yaitu metode deteksi tepi (edge detection) dan morfologi.

\section{Metode Penelitian}

Tahapan pada penelitian ini dapat merujuk pada alur penelitian yang akan dilakukan, seperti tampak pada gambar dibawah ini:

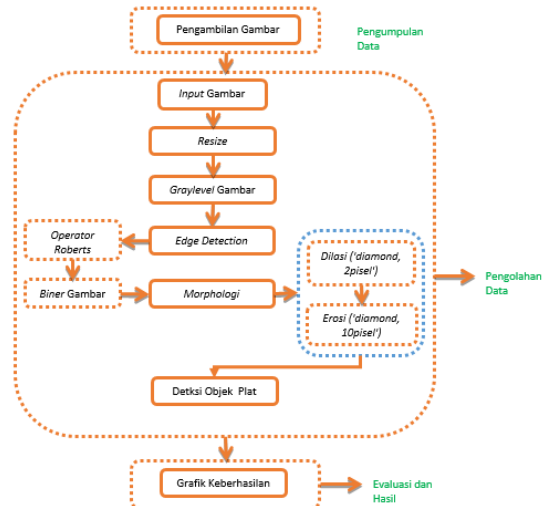

Gambar 1. Alur penelitian yang akan dilakukan mulai dari tahap awal hingga akhir

Seperti yang telah tertera pada gambar alur penelitian diatas maka tahapan pertama pada penelitian ini yaitu:

\section{Pengumpulan data}

Pengumpulan data dilakukan dengan mengambil image foto secara langsung pada lahan parkiran dengan perkiraan jarak $\pm 1 \mathrm{M}$, dengan menggunakan kamera dan tripot kamera 
agar image yang diambil tidak teralalu banyak mendapatkan gangguan atau noise.
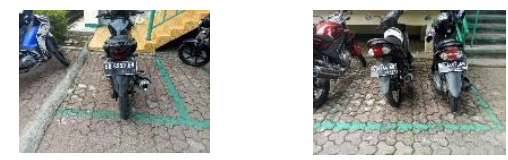

Gambar 2. Contoh hasil pengumpulan data uji yang akan dilakukan pada penelitian

\section{Pengolahan Data}

Pada proses ini akan dilakukan pengolahan data seperti pada alur penelitian yang diusulkan, dimana tahapannya sebagai berikut:

\section{a. Resize}

Pada tahapan ini akan dilakukan image resize, secara auto yang ditanamkan pada code MATLAB, dengan nilai resolusi 480 piksel untuk tinggi image, sedangkan untuk lebar image menyesuaikan hasil dari nilai tinggi resize yang telah ditentukan [2].

b. Graylevel Image

Pada tahapan ini akan merubah bentuk dari image 3D warna menjadi 2D warna yaitu gray, dimana tingkat keabuan didapatkan dari persamaan berikut [3]:

$$
\text { Grayscale }=(R+G+B) / 3
$$

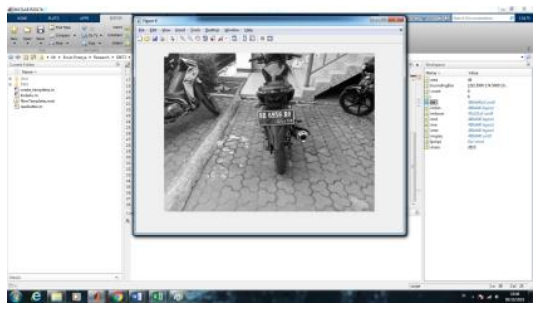

Gambar 3. Contoh hasil gambar graylevel 2D

\section{c. Edge Detection}

Dengan rata-rata nilai graylevel yang didapatkan untuk menjadi 2D warna image, maka selanjutnya akan dilanjutkan dengan proses deteksi tepi, dimana pada deteksi tepi ini akan mendapatkan nilai setiap tepi citra uji menggunakan operator roberts, dengan persamaan [4]:

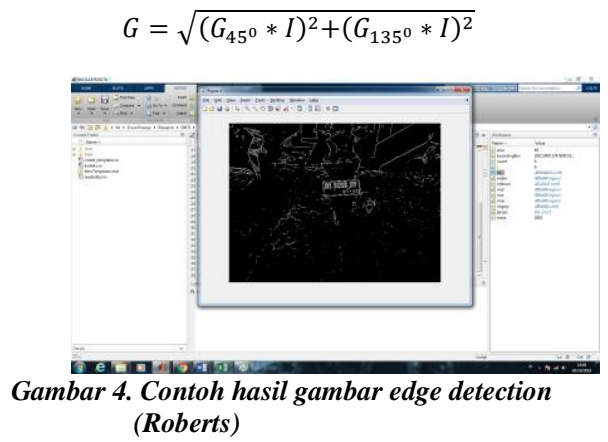

d. Morphologi

Pada tahapan ini akan memanfaatkan nilai deteksi tepi dari 2D warna agar dapat diproses deteksi plat yang dilakukan. Operator morphologi yang digunakan yaitu:

\section{a) Dilasi}

Pada proses dilasi dilakukan untuk menebalkan hasil deteksi tepi yang telah dilakukan sebelumnya, operator dilasi yang digunakan yaitu diamond dimana piksel diamond yang digunakan sebanyak 2 piksel sebaran diamond seprti pada contoh berikut [3]:
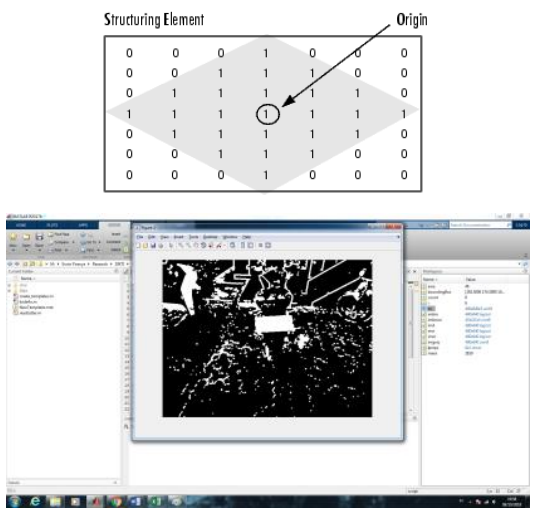

Gambar 5. Contoh proses dilasi 2 piksel, contoh hasil dilasi penelitian

b) Erosi

Selanjutnya akan digunakan operasi erosi sebanyak 10 piksel teknik diamond seperti halnya dilasi, hanya saja kenapa ditingkatkan sebanyak 10 piksel ketetanggan pada proses erosi akan dihilangkan noise yang tidak dibutuhkan akan dihilangkan, seperti contoh dibawah ini:

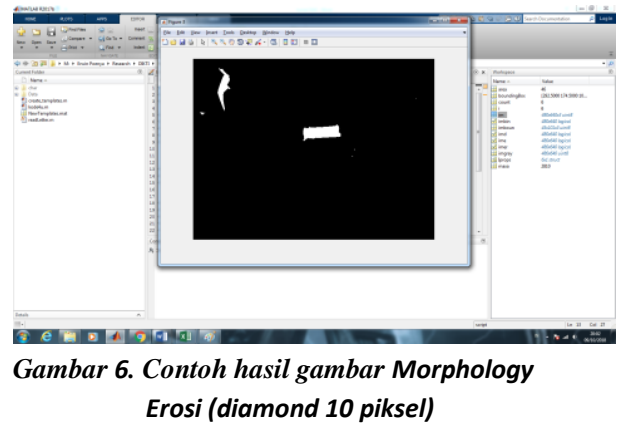


e. Deteksi Objek

Pada tahapan ini akan dideteksi objek plat nomor kendaraan dengan mengambil pemotongan objek image binerisasi persegi, dan pemotongan objek akan dikembalikan kepada image original, hasilnya sebagai berikut:

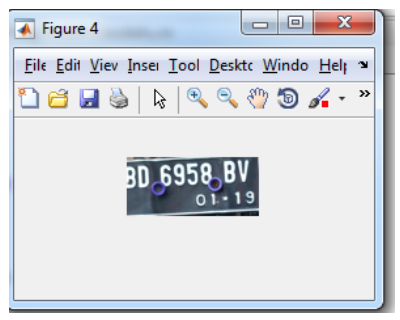

Gambar 7. Contoh hasil deteksi plat

\section{Evaluasi dan Hasil}

Pada penelitian ini evaluasi dan hasil penelitian akan dihitung menggunakan teknik confussion matrix, dimana pada teknik ini akan mengukur pada pendekatan tingkat keberhasilan yang akan didapat dari metode yang diusulkan, dengan persamaan [1]:

$$
\begin{aligned}
& \text { positive predictive value }=\frac{(T P)}{(T P)+(F P)} \\
& \text { negative predictive value }=\frac{(T N)}{(T N)+(F N)} \\
& \text { Accuracy }=\frac{\mathrm{TP}+\mathrm{TN}}{\mathrm{TP}+\mathrm{TN}+\mathrm{FP}+\mathrm{FN}}
\end{aligned}
$$

Dimana:

$\mathrm{Tp}=$ Plat terdeksi benar

$\mathrm{FP}=$ Jumlah plat seharusnya terdeteksi

$\mathrm{TN}=$ Jumlah bukan plat terdeteksi

$\mathrm{FN}=$ Jumlah plat yang tidak terdeteksi

\section{Hasil dan Diskusi}

Hasil dari penelitian ini akan dituangkan dalam bentuk hasil perhitungan yang dilakukan menggunakan proses perhitungan confusion matrix, seperti yang sudah dijelaskan sebelumnya. Penjelasan hasil perhitungan akan terlihat pada gambar berikut ini:

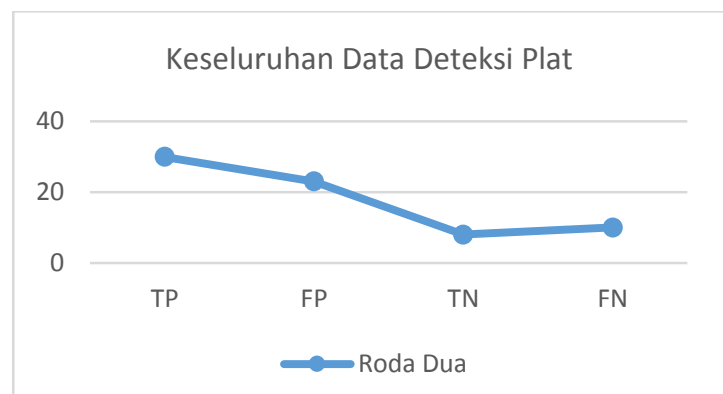

Gambar 8. Grafik keseluruhan data uji deteksi plat nomor kendaraan

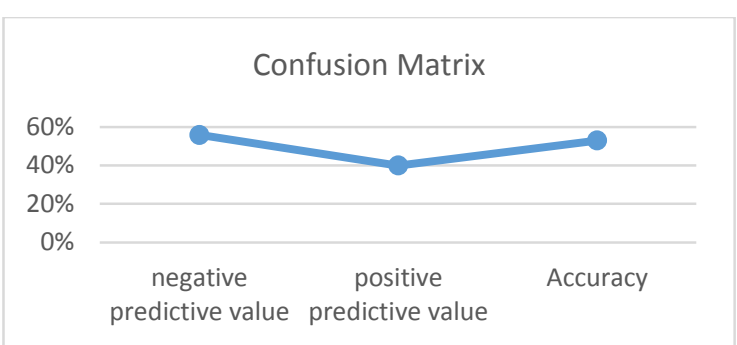

Gambar 9. Grafik hasil perhitungan confusion matrix

Dari hasil diatas dapat dibahas bahwa tingkat akurasi yang dihasilkan dari metode yang diusulkan cukup tinggi yaitu 53\% tingkat keberhasilan, sedangkan nilai positive predictive value dimana nilai ini untuk mengetahui tingkat keberhasilan metode untuk mendeteksi seluruh image uji masih sangatlah kurang hanya mencapai $40 \%$ keberhasilan, sedangkan nilai negative preditive value yang merupakan nilai untuk mengetahui pemisahan deteksi noise keberhasilannya cukup baik dengan nilai 56\% tingkat keberhasilan.

\section{Kesimpulan}

Hasil dari Confussion Matrix yang didapatkan masih sangat kurang pada akurasi roda empat $47 \%$ dan roda dua $53 \%$, dikarenakan data pada kendaraan roda dua seharusnya menggunakan image objek satu kendaraan, dan jarak pengambilan plat kendaraan roda dua lebih mendekati plat tersebut karena sangat terpengaruh oleh noise pantulan cahaya.

\section{Referensi}

[1] D. Abdullah dan E. D. Putra, "Komparasi Perbaikan Kualitas Segmentasi Pada Citra Digital Metode Fuzzy Cmeans Dan Otsu," Pseudocode, vol. 4, no. 1, pp. 71-80, 2017.

[2] A. Choudhury dan A. Negi, "A New Zone Based Algorithm for Detection of License Plate From Indian Vehicle," dalam nternational Connference on Parallel, 2016.

[3] E. D. Putra, D. A. Prabowo dan D. Abdullah, "Peningkatan Kualitas Citra Segementasi Objek Dari Permukaan Air Pada Metode Otsu Thresholding Dan Persamaan Gaussian," Informatika Upgris, vol. 3, no. 2, pp. 132-136, 2017.

[4] E. D. Putra, "Peningkatan Segmentasi Pada Identifikasi Plat Nomor Kendaraan Indonesia Menggunakan Metode Otsu Dengan Gaussian," Pseudocode, vol. 4, no. 1, p. 44, 2017.

[5] D. Abdullah dan E. D. Putra, "KOMPARASI METODE OTSU DENGAN METODE FUZZY CMEANS PADA HASIL SEGMENTASI IDENTIFIKASI KARAKTER PLAT NOMOR KENDARAAN INDONESIA," TELEMATIK, vol. 6, no. 4, p. 1475, 2013. 
[6] R. Serajeh, "Two Lines Iranian License Plate Detection and Recognition using Subspace Learning. Signal Processing and Intelligent Systems (ICSPIS)," dalam International Conference of. ISBN : 978-1-5090-5820-4, 2016.

[7] C. A. Roy, K. M. Hossen dan D. Nag, "License Plate Detection and Character Recognition System for Commercial Vehicles based on Morphological Approach and Template Matching," dalam IEEE, Dhaka, Bangladesh, 2016.

[8] E. D. Putra dan S. Santosa, "Optimasi Kemampuan Segmentasi Otsu Pada Identifikasi Plat Nomor Kendaraan Indonesia Menggunakan Metode Gaussian," Pseudocode, vol. 4, no. 1, pp. 47-60, 2017. 